\title{
Research on the index system of chemical enterprise safety risk state based on analytic hierarchy
}

\author{
Fei $\mathrm{Wu}^{1 *}$, Ling Cheng ${ }^{2}$, Yinglei Yu ${ }^{3}$, Jiajia $\mathrm{Sun}^{4}$ \\ 1,2,3,4 Jiangsu Academy of Safety Science and Technology, Jiangsu, Nanjing 210042
}

\begin{abstract}
Based on the 19 selected representative chemical enterprises in jiangsu province, we investigate the safety risk situation of chemical enterprises from the aspects of personnel technical level, equipment failure, major hazard sources, production process, environment, accident, certification, safety assessment and emergency response capacity. We found the following problems: the most part of staffs education is below undergraduate course; have major hidden dangers at district/county level and above; the vast majority of enterprises of dangerous chemicals maximum action/reaction temperature over dangerous chemicals flash point, etc. The index system of chemical enterprise safety risk state is constructed from six aspects: personnel, equipment, material, method, environment and safety management. The key index system of security risk state warning is put forward from the aspects of personnel, equipment, method, environment and safety management. We use the analytic hierarchy process (AHP) method to determine the chemical enterprise safety risk status indicators weight, and finally determine the state of the chemical enterprise safety risk classification standard.
\end{abstract}

\section{Preface}

In the past three years, the major explosion of the "12•9" dichlorobenzene device of Jiangsu Lianyungang Juxin Biotechnology Co., Ltd., and the particularly major explosion of "March 21" caused by the illegal storage of hazardous waste by Xiangshui Tianjia Chemical Co., Ltd., have caused great social impact and huge economic losses. The characteristics of chemical production safety accidents [1-6] are mainly determined by the characteristics of raw materials used in the production process, the degree of operation norms, the processing technology methodology and the size of the production scale.

At present, there are 2,481 enterprises in Jiangsu Province that have obtained the safe production license for hazardous chemicals, involving chemical, petrochemical, pharmaceutical manufacturing and other chemical industries. Hazardous chemical enterprises are widely distributed, which not only have the advantages of large scale, complete categories, numerous varieties, professional supporting, and high degree of coordination of industrial system, but also face the disadvantages of low level of enterprise development, poor level of safety and environmental protection, including insufficient security risk monitoring etc., especially in the following two aspects: one is the enterprise security risk problem is relatively common. There are many kinds of chemical industry and complex process. There are many conditions and factors such as high temperature and high pressure, flammable and explosive in the production process. Quite a number of hazardous chemical enterprises safety risk beyond effective control and wander in the critical or even out of control state.Most of them are listed as follows: the safety management mechanism has not been established or has not been effectively operated, the safety level is low, the safety consciousness is not strong enough, the mobility of employees is large, the safety facilities are outdated and backward, the science and technology content is low, the accident emergency rescue level is low, the ability is poor, etc. Therefore, the possibility and harmfulness of accidents can not be underestimated, and the prevention and control of safety risks can not be ignored. Second, the regional security risks caused by the unreasonable regional layout of the chemical industrial park may lead to the crisis of major accidents. During the "12th Five-Year Plan" period, the chemical industry of Jiangsu Province extends to the south and north of Jiangsu with the Yangtze River as the central axis, focusing on the chemical industrial belt along the Yangtze River, the coastal chemical industrial belt, and the chemical industrial belt for resource development and utilization. The occupancy rate of chemical production enterprises is still low in our province. Most dangerous chemicals industry in our province units are along the Yangtze river, the river, lake and coastal areas. More than $70 \%$ of the chemical industry, chemical industry park is concentrated in the areas along the river, " Chemical enterprises surround the Yangtze River " problems is outstanding. Once hazardous chemical production accident occurs, it is easy to cause chain accidents and pollution of water system environment, and then cause disastrous

*Corresponding author's e-mail: G0211@njtech.edu. 
consequences.

Based on the analytic hierarchy process (AHP), the index system of the safety risk state of chemical enterprises is established in this paper to promote the safety of chemical enterprises production and effectively prevent dangerous chemical production accidents, especially to eliminate the occurrence of serious accidents.

\section{Establishment of index system}

Qi Cheng et al. [7] established a risk grade evaluation index system for hazardous chemical processes from the aspects of inherent hazards and safety compensation. Feng $\mathrm{Wu}$ et al. [8] used fuzzy Petri net and fuzzy reasoning algorithm to construct the evaluation index system of dangerous goods transportation safety from the aspects of transportation cost, accident risk, disaster-causing and remedial ability. Deshun Li et al. [9] used AHP to determine the weight of fire risk pattern recognition index of petrochemical enterprises from five aspects, including production process, storage process, transportation process, fire protection facilities and safety management. Yu Qian [10] used independent component analysis to analyze the state space of chemical process system. Dengyou Xia et al. [11] constructed an evaluation index system for the significance degree of storage tank characteristics by using AHP and multi-level fuzzy evaluation. Gong Bo et al. [12] determined the weight of iron ore hazard evaluation index based on the extension analytic hierarchy process.

By far the most influential cause of loss in chemical plants is mechanical failure, such as pipe failure due to corrosion, erosion, overpressure, sealing surface or gasket failure, etc. This type of failure is usually caused by lack of maintenance or lack of utilizing principle of intrinsically safety and process safety management. If not properly maintained, pumps, valves, and other control equipment will fail. The second most common cause is operational errors, such as valves not opening or closing in the correct sequence, or reactants not being released into the reactor in the correct sequence. Process disturbances due to a variety of energy or cooling water failures account for $3 \%$ of the loss. Figure 1 shows the causes of chemical accidents that cause heavy losses [13].

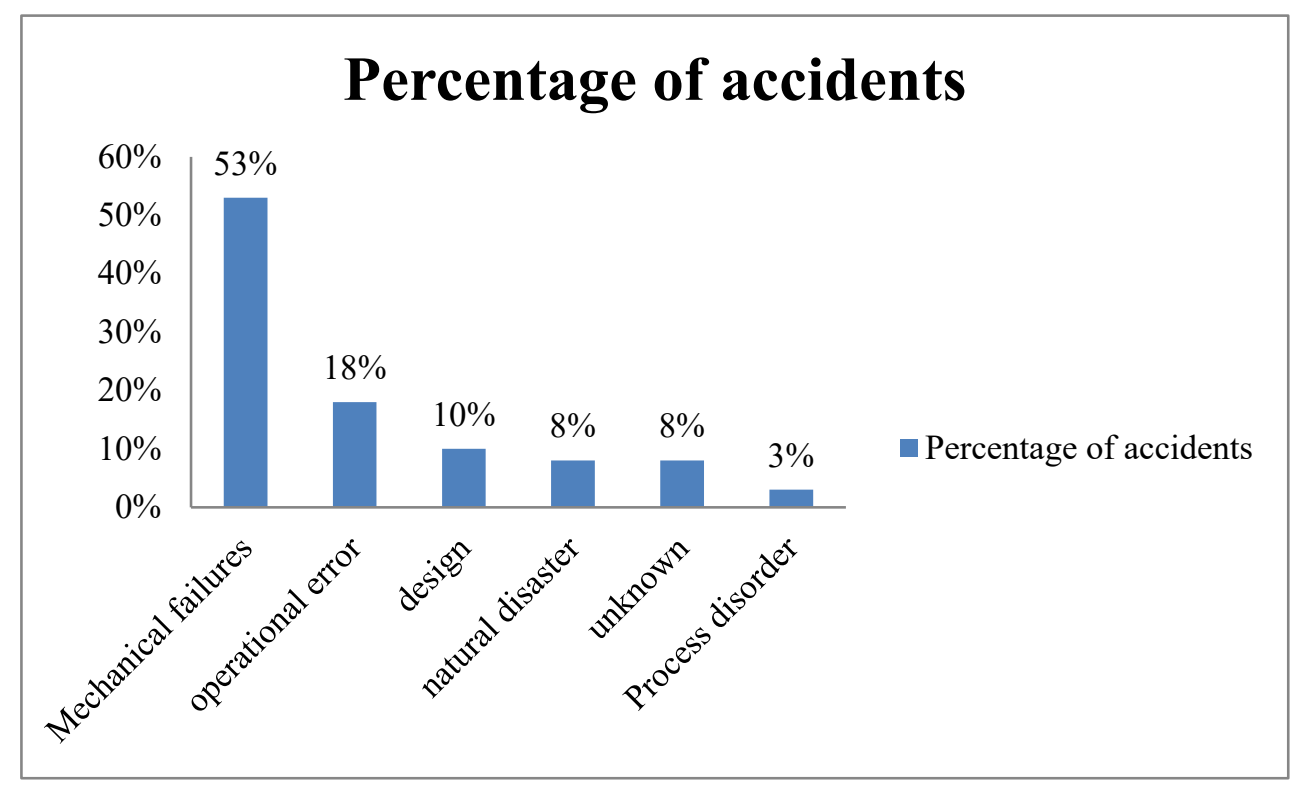

Figure1.Causes of loss caused by accidents at large petrochemical plants

Human error is often used to explain the causes of losses, and almost all accidents except those caused by natural disasters can be attributed to human error. For example, mechanical failures can be attributed to human error due to the failure to properly maintain or inspect.

\subsection{The research analysis}

Based on the principle of random sampling, 19 representative chemical enterprises in Jiangsu Province were selected to investigate the safety risks of chemical enterprises from the aspects of personnel technical level, equipment failure, major hazard sources, production process, environment, accident, certification, safety assessment and emergency response capacity.

\subsubsection{The staff}

Questions about the enterprise personnel degree level. In the recycling survey form of 19 enterprises, 1 have no bachelor degree security administrator, 19 involving "a focus of the two major" operators have more than college or equivalent, the security administrator in the total number of employees accounted for $2.7 \%$, which has a college degree security administrator account for $2.6 \%$, with bachelor degree or above $1.4 \%$ security administrator. This indicates that in the research enterprises, the vast majority of employees have a bachelor's degree or below, and the educational level is low. 


\subsubsection{Equipment situation}

In terms of safety facility inspection, the selected enterprises have carried out regular inspection.15 enterprises have received feedback on the total number of $\mathrm{A}, \mathrm{B}$ and $\mathrm{C}$ equipment and the number of various equipment failures in recent 5 years. In the past five years, 16 enterprises received feedback on the number of unplanned stops and the total number of stops. There are 18 enterprises that have received feedback on whether important equipment has fault warning technology, among which 1 enterprise does not have fault warning technology for important equipment. See Table 1 for detailed data.

Table1. Statistical table of important equipment with fault early warning technology

\begin{tabular}{cc}
\hline $\begin{array}{c}\text { Important equipment with } \\
\text { fault warning technology }\end{array}$ & $\begin{array}{c}\text { Enterprises involved (home } \\
\text { owners) }\end{array}$ \\
\hline The compressor & 13 \\
Machine pump (pump set) & 10 \\
\hline
\end{tabular}

\begin{tabular}{cc}
\hline $\begin{array}{c}\text { The reactor } \\
\text { Reaction equipment } \\
\text { (kettle) }\end{array}$ & 11 \\
$\begin{array}{c}\text { Physical separation } \\
\text { equipment (distillation) } \\
\text { Storage tank } \\
\text { other }\end{array}$ & 12 \\
& $\begin{array}{c}\text { 2(Air compressor, } \\
\text { refrigerating unit) }\end{array}$ \\
\hline
\end{tabular}

In terms of major hidden dangers at district/county level and above in the last 5 years, 4 out of the 19 feedback enterprises have major hidden dangers at district/county level and above and have completed the rectification.

\subsubsection{Material condition}

In terms of major hazard sources, there is 1 major hazard source that does not involve storage unit and production unit. See Figure 2-3 for detailed data.

\section{Major hazard level of storage unit}

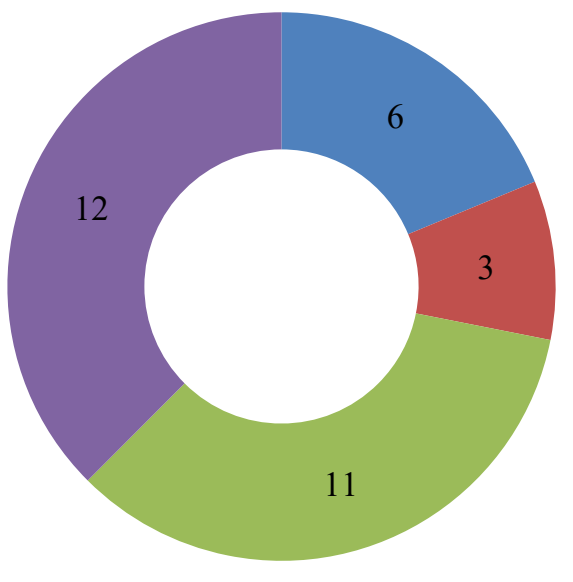

a first level

- second level

- third level

- fourth level

Figure 2. Major hazard level of storage unit

\section{Major hazard levels of production units}

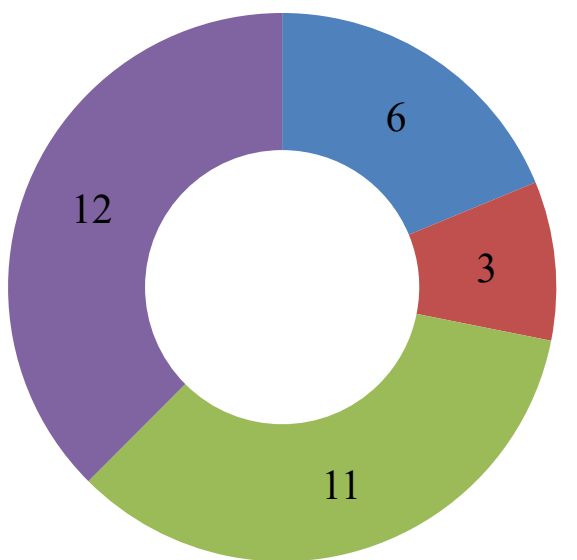

first level

n second level

third level

fourth level

Figure 3. Major hazard levels of production units 


\subsubsection{Methods case}

In terms of hazardous chemicals, 18 enterprises received feedback on hazardous chemicals, and all of them had the situation that the maximum operation/reaction temperature of hazardous chemicals exceeded the flash point of hazardous chemicals.

In terms of hazardous chemical processes under key supervision, all the research enterprises have hazardous chemical processes under key supervision. See Figure 4 for detailed data.

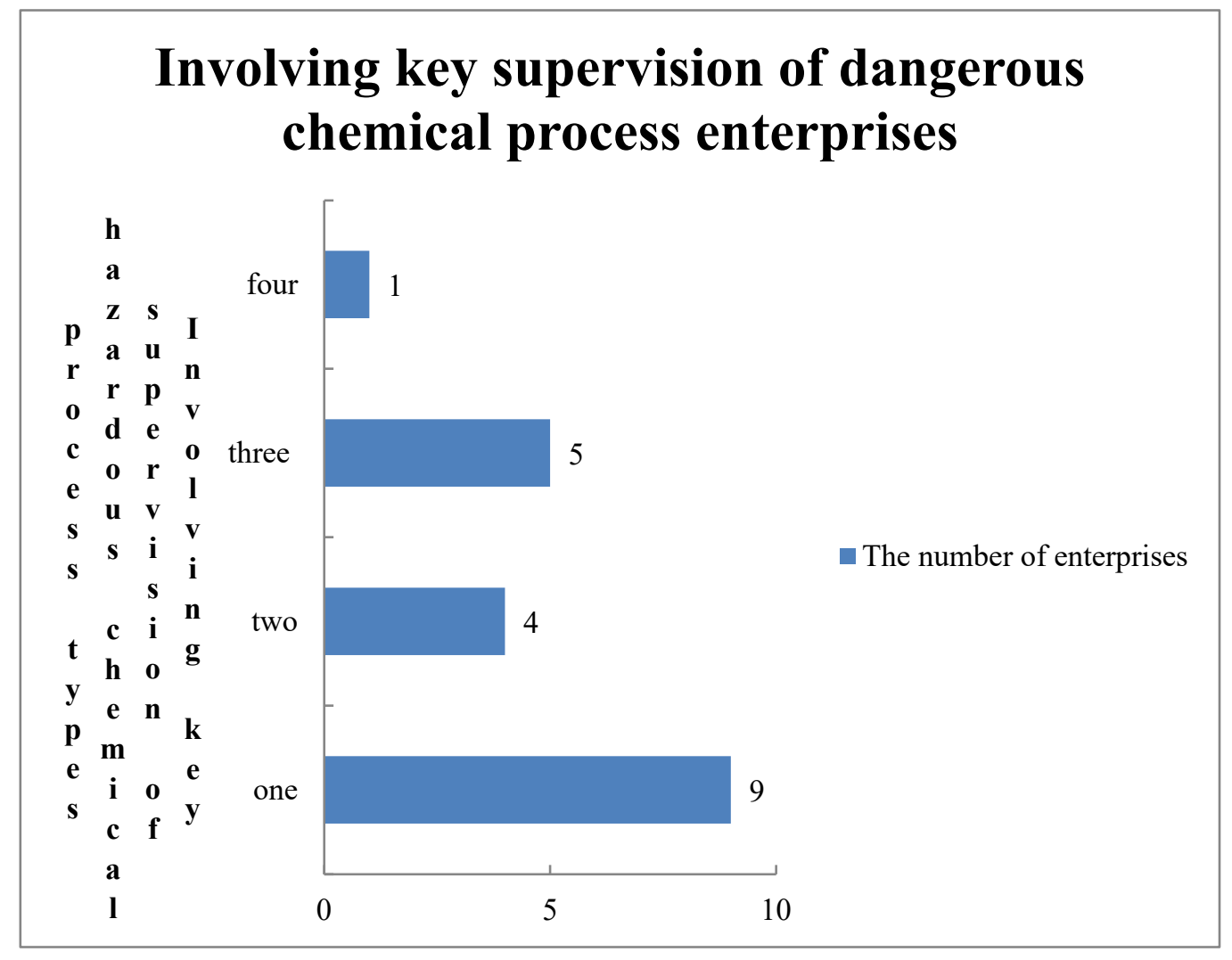

Figure 4. Enterprises involving key types of hazardous chemical processes under supervision

In terms of carrying out HAZOP by PID, 15 enterprises received feedback, among which 11 enterprises carried out HAZOP by $100 \%$ of PID.

In terms of whether HAZOP and LOPA are related to SIS, 17 enterprises have received feedback, among which 13 enterprises are determined to do LOAP in HAZOP and SIS based on LOAP, and the remaining 4 enterprises are determined to do LOAP in HAZOP.

In terms of major hidden danger of process, there are 18 enterprises receiving feedback, none of which have any major hidden danger of process.

\subsubsection{Environmental conditions}

In terms of the internal environment of enterprises, 12 enterprises gave feedback on the number of personnel within the personal risk isoline, while the evaluation reports of the remaining 7 companies did not use image form to calculate personal risk or the image used could not see the boundary of the isoline.

In terms of the external environment of enterprises, due to the concentration of enterprises in this survey, there is little difference in the number and grade of protection targets within $500 \mathrm{~m}$ outside the boundary of enterprises, which are all located in chemical industrial parks or concentrated areas of chemical industry.

In group $\mathrm{a}, \mathrm{b}$ unit with the control room and no explosion-proof design, explosive hazardous chemical device with the control room and no explosion-proof design, there are number of party $a$ and $b$ sites do not conform to the requirements, major hidden dangers exist surrounding environment design and so on, 19 companies all have feedback, including 1 company exist with party a and b class device has control room and no explosion proof design.

\subsubsection{Management situation}

In terms of the number of deaths, serious injuries and personnel in the last 5 years, 14 enterprises have received feedback, and the detailed data are shown in Table 2.

Table 2. Statistical table of the types of accidents in enterprises

\begin{tabular}{cc}
\hline The accident types & $\begin{array}{c}\text { Enterprises involved (home } \\
\text { owners) }\end{array}$ \\
\hline Deadly accident & 2 \\
Number of fatal accidents & 3 times \\
The number of dead totals & 4 people \\
Serious injury accident & 1 \\
Number of serious injuries & 1 time \\
\hline
\end{tabular}




\begin{tabular}{cc}
\hline $\begin{array}{c}\text { Total number of serious } \\
\text { injuries }\end{array}$ & 2 people \\
\hline
\end{tabular}

In terms of safety standardization, there are 18 enterprises receiving feedback, and the level of safety standardization is level two.

In the aspect of safety assessment, there are 13 enterprises that get feedback, and the proportion is $10 \%$, $20 \%, 30 \%$ and others respectively.

In terms of emergency preparedness capacity assessment, 18 enterprises have received feedback, of which 17 have all carried out emergency preparedness capacity assessment.

In terms of the enterprise five-in-one system, 19 feedback enterprises, 1 enterprise has not filled in the acceptance, 3 have completed the acceptance, 15 have not completed the acceptance; eight enterprises have alarm data, and the detailed data are shown in Figure 5.

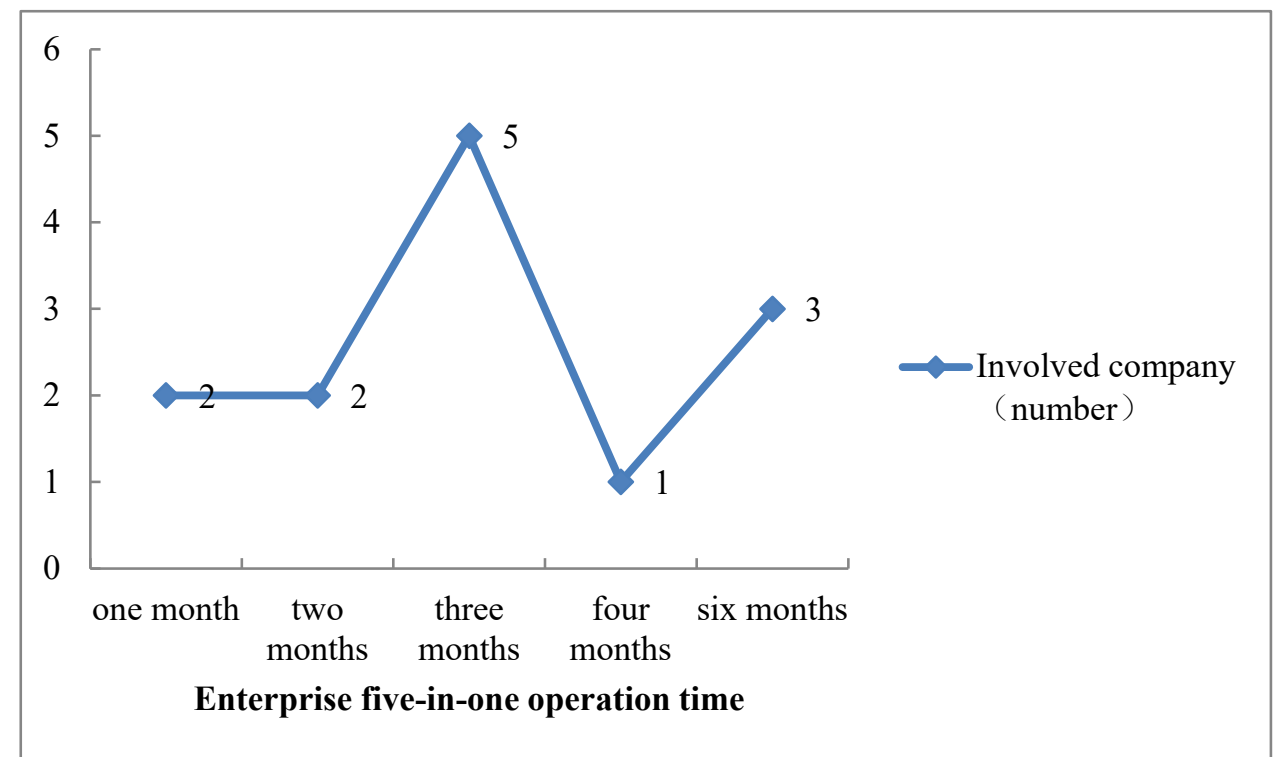

Figure 5. Enterprise five-in-one operation time statistics

In terms of major hidden dangers in the past five years, 8 of the 19 enterprises reported have major hidden dangers, with a total of 17 major hidden dangers.

In terms of other major hidden dangers, non-implementation of change management, and the existence of super-grade or first-level hot work that did not meet the requirements, 1 out of the 19 feedback enterprises had the hot work that did not meet the requirements because they did not implement the third-party service.

\subsection{Indicators establishment}

Based on the survey data, the key factors affecting the safety risk of chemical enterprises are screened out from six modules of "Human-Machine and Material Method" and evaluated by consulting experts. The key factors influencing the safety risk of chemical enterprises were screened out, and the index system of the safety risk state of chemical enterprises was constructed, as shown in Table 3.

Table 3 Safety risk state index system of chemical enterprise

\begin{tabular}{|c|c|c|}
\hline $\begin{array}{l}\text { Level } \\
\text { indicators }\end{array}$ & $\begin{array}{l}\text { The secondary } \\
\text { indicators }\end{array}$ & The third indicators \\
\hline \multirow{9}{*}{ Personnel } & \multirow{7}{*}{ The technical level } & $\begin{array}{l}\text { The proportion of operators involved in "two key and one major" with high school or } \\
\text { equivalent education or above }\end{array}$ \\
\hline & & $\begin{array}{l}\text { The proportion of safety management personnel with college and equivalent education } \\
\text { or above }\end{array}$ \\
\hline & & Ratio of qualified personnel in HR assessment (\%) \\
\hline & & Satisfaction with various types of training $(\%)$ \\
\hline & & Starting number of illegal operations/(number of people on site $*$ duration) \\
\hline & & The proportion of safety management personnel with working years of 5 years or above \\
\hline & & The failure rate of class $A$ equipment in recent 5 years \\
\hline & & The failure rate of class $\mathrm{B}$ equipment in recent 5 years \\
\hline & & The failure rate of class $C$ equipment in recent 5 years \\
\hline \multirow[t]{2}{*}{ Equipment } & Equipment failure & Number of unplanned stops/total stops \\
\hline & & $\begin{array}{l}\text { Compressor, machine pump (pump group), reactor, reaction equipment (kettle), physical } \\
\text { separation equipment (distillation unit), storage tanks and other important equipment } \\
\text { with fault warning technology }\end{array}$ \\
\hline Material & Source of major & Level of significant hazard in storage unit \\
\hline
\end{tabular}




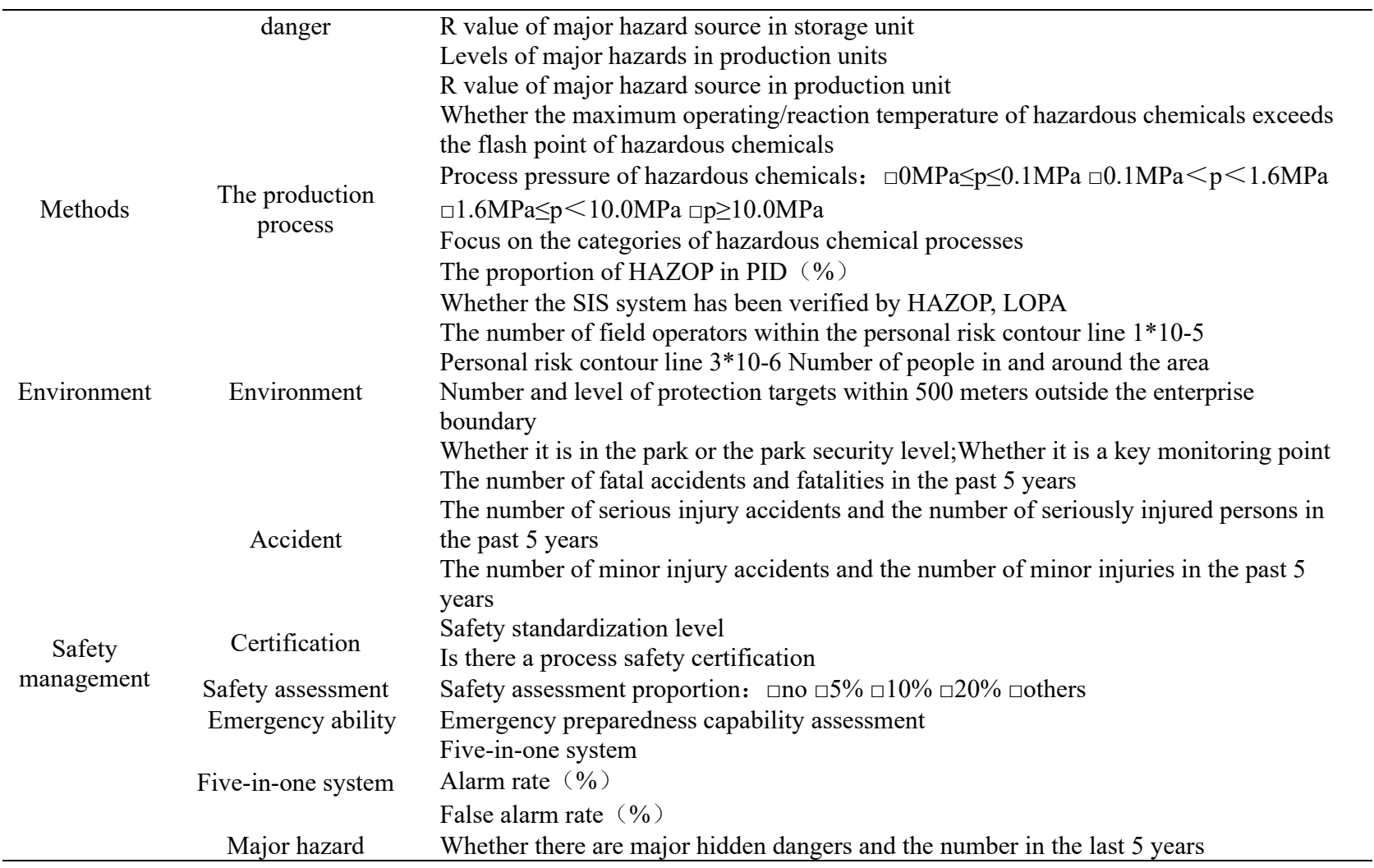

\subsection{Index weight calculation based on analytic hierarchy process}

Based on the survey data, the analytic hierarchy process [14] is used to calculate the constructed weight of all levels of indicators of the safety risk state of the chemical enterprise. AHP method is divided into five steps:

1. Establish target layer, criterion layer and index layer;

2. construct the judgment matrix. The relative importance of each index belonging to the same index is compared to form a judgment matrix.For example, for the index $V_{j}(I=1,2 \ldots, m)$, whose judgment matrix is a one-dimensional square matrix $B=\left(b_{i j}\right)_{m \times m}$. $b_{i j}$ represents the relative importance of pair-to-pair-to-pair-to-index comparison among all indicators belonging to index $\mathrm{V}$ using the 1-9 scale method.

3. Solve eigenvalues and eigenvectors. In the judgment matrix $B=\left(b_{i j}\right)_{m \times m}, \quad b_{j i}=1 / b_{i j}(i, j=1,2, \ldots$, $\mathrm{m}), \quad \mathrm{b}_{\mathrm{ij}}>0, \quad \mathrm{~b}_{\mathrm{ii}}=1$,

$$
\omega^{(k)}=\left(\omega_{1}^{(k)}, \omega_{2}^{(k)}, \ldots, \omega_{n k}^{(k)}\right)=p^{(k)} \omega^{(k-1)}=p^{(k)}\left(\omega_{1}^{(k-1)}, \omega_{2}^{(k-1)}, \ldots, \omega_{n k-1}^{(k-1)}\right)
$$

Among them, $\omega^{(k)}$ — The composite ordering weight vector of $\mathrm{nk}$ elements on the $\mathrm{k}$ layer for the total target;

$p^{(k)}$ _ Nk elements on the $\mathrm{k}$ layer are the ordering weight vector of the criterion for all elements on the $k-1$ layer.

$\omega^{(k-1)}$ _ The composite ordering weight vector of nk-1 elements on the k-1 layer for the total target.

The enterprise safety risk value $\mathrm{R}$ is weighted by the scores of personnel risk level, equipment risk level,

$$
b_{i j}=b_{i k} * b_{k j}(\mathrm{k}=1,2, \ldots, \mathrm{m})
$$

4. Consistency checking. When the order is greater than 2, it can be verified by calculating the random consistency ratio $\mathrm{Cr}$, whose calculation formula is

$$
C R=\frac{\lambda_{\max }-m}{(m-1) R I}
$$

Among them, RI is the average random consistency index.

When $C R=\frac{\lambda_{\max }-m}{(m-1) R I}<0.1$, the judgment matrix has acceptable inconsistency; Otherwise, it is considered that the judgment matrix initially established is unsatisfactory, and the value should be re-assigned and carefully corrected until the consistency test is passed.

5. Calculation of composite weights. The total ranking coefficient of the hierarchy is calculated, and the weight of a single criterion is synthesized from top to bottom, layer by layer, until the weight of each element in the bottom layer and the total consistency test are calculated, namely material risk level, method risk level, environment risk level and management risk level : $\mathrm{R}=R_{P}+R_{M}+R_{G}+R_{C}+R_{E}+R_{R}$

Among them: $\mathrm{R}$-Enterprise security risk value; $R_{P} \longrightarrow$ Personnel risk level; $R_{M} \longrightarrow$ Machine risk level; $R_{G}-$ Material risk level; $R_{C}-$ Method risk level; $R_{C}$ Environmental risk level; $R_{R}$-Manage risk levels.

For example, the risk level score of enterprise personnel: $R_{P}=\sum_{i=1}^{N} B_{i} W_{i}=\sum_{i=1}^{N}\left(\sum_{i=1}^{m_{i}} C_{i j} W_{i j}\right) W_{i}$ 
Among them: $R_{P}$ is the risk level of personnel; $\mathrm{N}$ is the number of secondary indicators included in personnel risk; $B_{i}$ represents the second-level index score of personnel risk in item $i$; $W_{i}$ represents the second-level index weight of personnel risk in item $i ; \mathrm{m}_{\mathrm{i}}$ is the number of three-level indicators of personnel risk in item $\mathrm{i} ; \mathrm{C}_{\mathrm{ij}}$ represents the score of $\mathrm{j}$ three-level index in $\mathrm{i}$ item of personnel risk; $\mathrm{W}_{\mathrm{ij}}$ represents the weight of three-level index $\mathrm{j}$ in item $\mathrm{i}$ of personnel risk. Equipment risk level, material risk level, method risk level, environment risk level, management risk level and so on.

See Table 4 for the weight calculation results of all levels of indicators of enterprise security risk status.

Table 4. Enterprise security risk state secondary index weight calculation

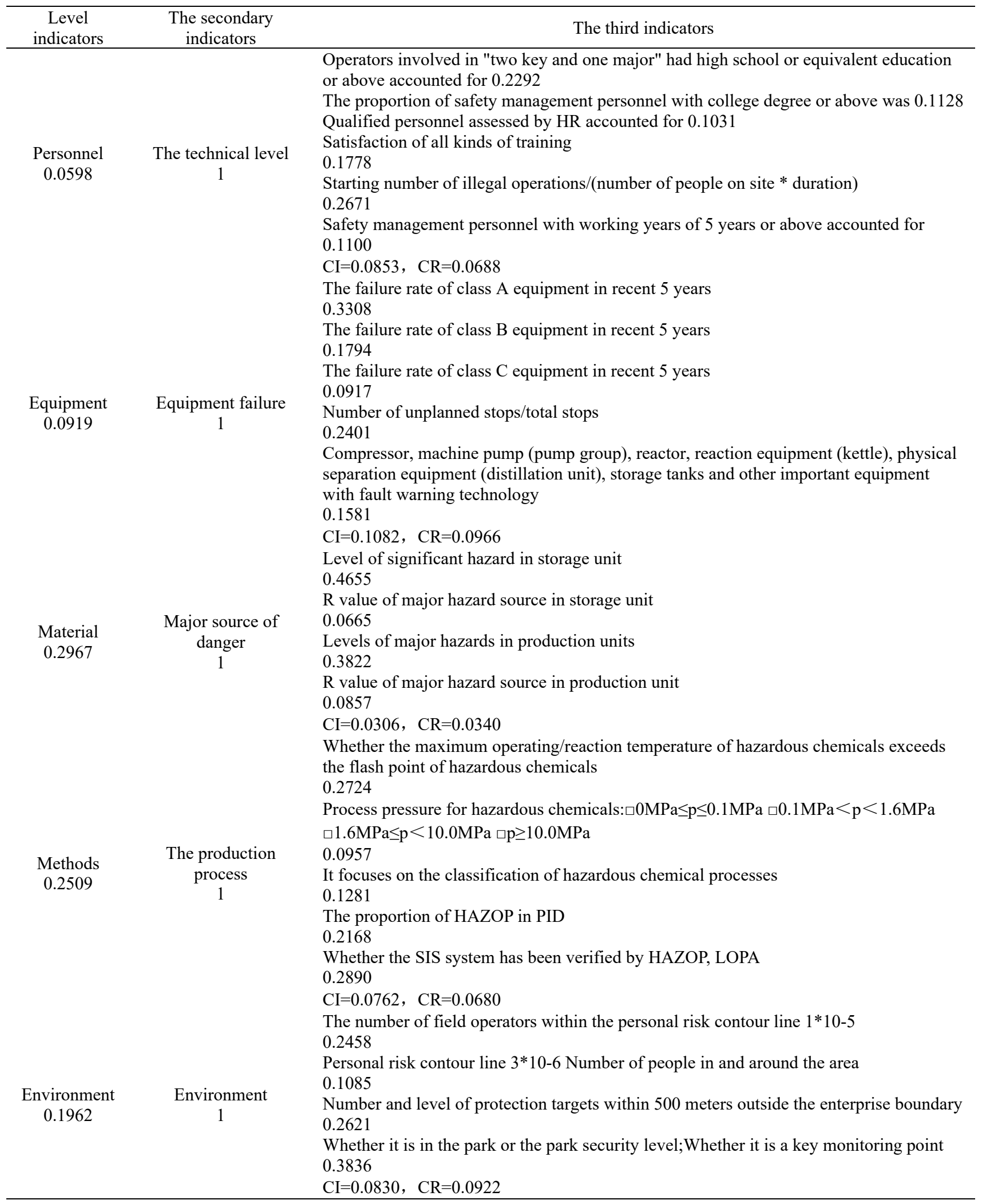




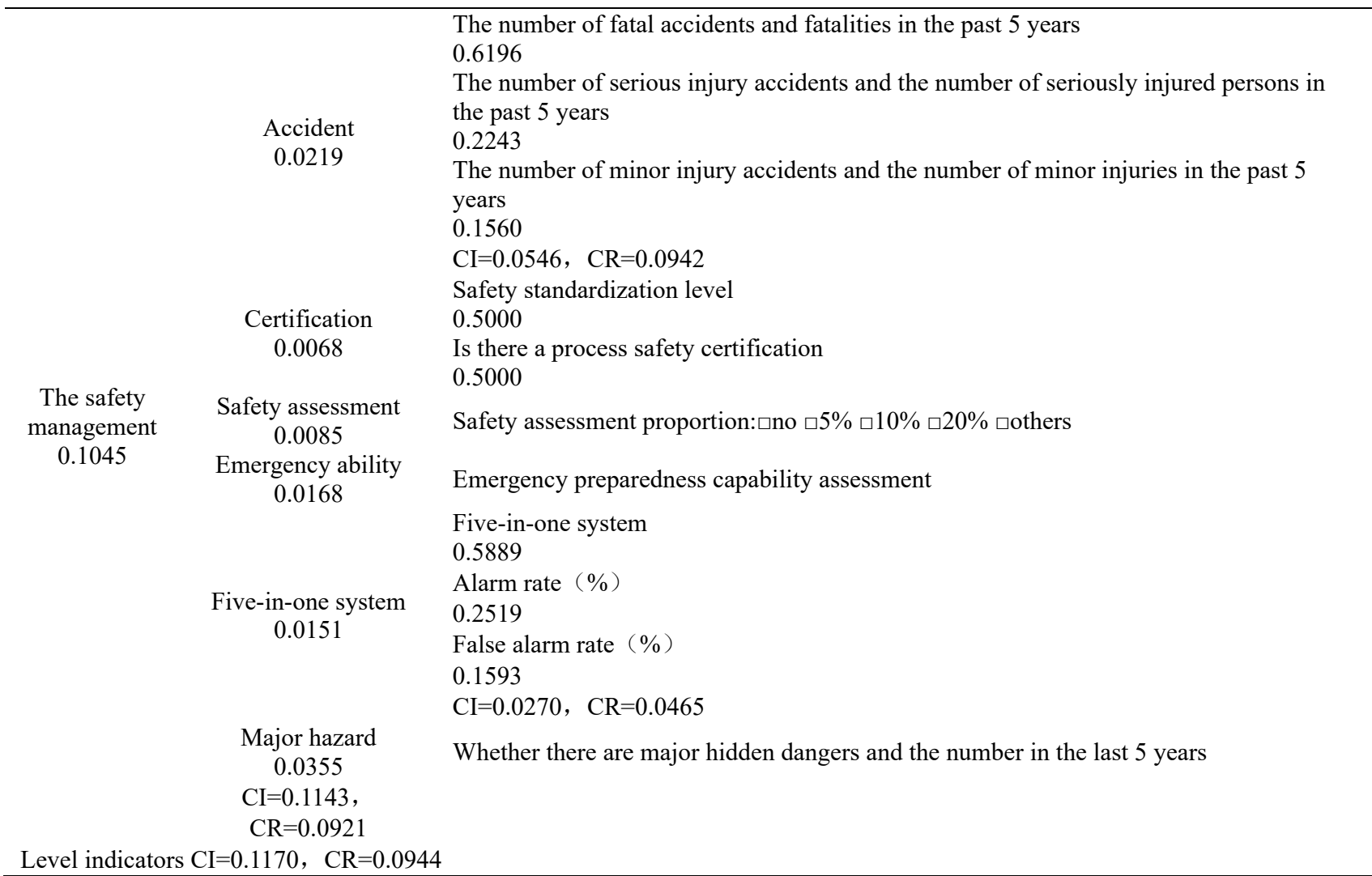

According to the results of enterprise safety risk calculation, the safety risk states of chemical enterprises are divided into three states: safe, critical and unsafe, as shown in Table 5 .

Table 5. Classification criteria for safety risk state of chemical enterprises

\begin{tabular}{cc}
\hline $\mathrm{R}$ & Security risk status level \\
$\geq 65$ & security \\
$50 \sim 65$ & critical \\
$\leq 50$ & unsafe \\
\hline
\end{tabular}

According to the characteristics of chemical enterprises and the actual situation of investigation, the key index system of safety risk state early warning is proposed from the aspects of personnel, equipment, method, environment and safety management, as shown in Table 6. Key index systems are all binding indicators, that is, as long as there is one or more indicators, the critical state is directly judged.

Table 6. Key index system of security risk state warning

\begin{tabular}{|c|c|c|c|}
\hline $\begin{array}{c}\text { Level } \\
\text { indicators }\end{array}$ & $\begin{array}{c}\text { Serial } \\
\text { number }\end{array}$ & High Risk Key Indicators & Note \\
\hline \multirow{5}{*}{ Personnel } & 1 & Special equipment personnel did not hold a certificate to work & Binding target \\
\hline & 2 & No registered safety engineer & Binding target \\
\hline & 3 & Non-hazardous process operation certificate involving high-risk process & Binding target \\
\hline & 4 & Mainly responsible for non-chemical, safety related majors & Binding target \\
\hline & 5 & Maintenance cycles are not strictly enforced & Binding target \\
\hline \multirow{3}{*}{ Equipment } & 6 & The equipment runs with disease & Binding target \\
\hline & 7 & Safety facilities are not tested for reliability as required & Binding target \\
\hline & 8 & Major hidden danger of other equipment & Binding target \\
\hline \multirow[t]{2}{*}{ Methods } & 9 & Major hidden danger of process & Binding target \\
\hline & 10 & $\begin{array}{c}\text { Class A and class B devices are equipped with a control room and no } \\
\text { explosion-proof design }\end{array}$ & Binding target \\
\hline \multirow[t]{2}{*}{ Environment } & 11 & $\begin{array}{l}\text { Explosive hazardous chemical device is equipped with control room and } \\
\text { explosion-free design }\end{array}$ & Binding target \\
\hline & 12 & There are major hidden dangers such as surrounding environment design & Binding target \\
\hline \multirow{3}{*}{$\begin{array}{c}\text { Safety } \\
\text { management }\end{array}$} & 13 & Other Major Hazards & Binding target \\
\hline & 14 & Change management is not implemented & Binding target \\
\hline & 15 & Extra grade, first grade fire does not meet the requirements & Binding target \\
\hline
\end{tabular}




\section{Conclusion}

(1) When the safety risk state of a chemical enterprise is finally determined to be critical, the enterprise shall strengthen the following measures:

The first is personnel. Enterprises should carry out professional safety training, emergency knowledge and skills training, implement the responsibility awareness to individuals, reduce the probability of accident hidden danger caused by improper entity operation; strictly implement special equipment and high-risk technology, and replace the main person in charge of the enterprise with chemical and safety-related majors if conditions permit.

The second is equipment. Enterprises should find all kinds of equipment failure reasons, reduce the failure rate of equipment; Key equipment is equipped with fault warning technology step by step, strictly implement equipment maintenance cycle, and carry out regular inspection of safety facilities;

The third is the method. The enterprise updates the process safety information on time and develops written operating procedures, so that the operators understand the process parameters and right operating procedures.

The fourth is environment Enterprises improve the level of automation, as far as possible to reduce the number of on-site personnel within the isoline of $1 * 10-5$ personal risk.

The fifth is safety management。Carry out process safety certification if possible, and improve safety standardization level according to the actual situation of the enterprise; Improve the proportion of safety assessment; Accelerate the acceptance of enterprise five-in-one system and reduce false alarms.

(2) When the safety risk state of a chemical enterprise is finally determined to be unsafe, the enterprise shall immediately stop production and take the following measures:

The first is personnel. Carry out professional safety training, emergency knowledge and skills training, implement the responsibility awareness to individuals, reduce the probability of accident hidden danger caused by improper entity operation; Strictly implement special equipment and high-risk technology with certificates, and replace the main person in charge of the enterprise with chemical industry and safety related majors.

The second is equipment. Find all kinds of equipment failure reasons, reduce the failure rate of equipment; Key equipment is equipped with fault warning technology, strictly implement the equipment maintenance cycle, and regular inspection of safety facilities;

The third is the material. The enterprise shall reduce the usage amount and storage amount of hazardous chemicals in production and storage units, and reduce the level and $\mathrm{R}$ value of major hazardous sources.

The fourth is method. Enterprises look for safer processes to replace; Update process safety information timely and develop written operating procedures, so that operators understand the process parameters and correct operating procedures.

The fifth is environment. Enterprises improve the level of automation and reduce the number of personnel within the contour lines $1 * 10-5$ and $3 * 10-6$ of personal risk.

The sixth is management. Carry out process safety certification, and improve safety standardization level according to the actual situation of the enterprise; improve the proportion of safety assessment; accelerate the acceptance of enterprise five-in-one system and reduce false alarms.

\section{Acknowledgments}

The authors are grateful for the financial support given by the Innovation development plan-Independent research project of Jiangsu Academy of Safety Science and Technology (BM2018025).

\section{References}

1. DU Hong-yan,WANG Yan-ping,LU Jun-chen.Statistical analysis on petroleum and chemical accidents at home and abroad during the period of 2012.Journal of Safety Science and Technology,2013, 9 (6) :184-188。

2. Yongfeng Ye, Xin Xia, Zhuxia Li.Statistical Analysis of Typical Safety Accidents in Chemical Industry [J]. Industrial Safety and Environmental Protection,2012, (09): 49-51.

3. Kang Sun, Hongmin Yang. Statistical Analysis of Dangerous Chemical Accidents in China [J]. Fire Technology, 2012, (48):331-341

4. Yun Luo, Haiyan Lu, Fili Bai.Accident Analysis and Prediction and Management [M]. Beijing;Chemical Industry Press,2006, 15-33.

5. Ruihua Lv, Xiaodong Zhang. Statistical analysis and grey prediction of production safety Accidents [J]. Journal of Chemical and Pharmaceutical Research, 2014,6(8): 456-461.

6. Yong Jeong B. Comparisons of variables between fatal and nonfatal accidents in manufacturing industry $[\mathrm{J}]$. International Journal of Industrial Ergonomics, 1999, 23(5): 565-572.

7. Qi Cheng, Yanqiu Guo,Lijing Zhang et al.Study on Evaluation Index System of Risk Grade of Hazardous Chemical Process in Petrochemical Enterprises [J]. China Safety Science and Technology, 2011, 7 (10): 89-92.

8. Feng Wu, Xiaoyan Wang.Safety Assessment Model of Dangerous Goods Transport Based on Fuzzy Petri Net and Its Application [J]. China Safety Science Journal.2011, 21 (1): 93-98.

9. Deshun Li, Bo Gong, Kaili Xu.Research on Fire Risk Pattern Recognition Model of Petrochemical Enterprises [J].China Science and Technology of Production Safety, 2012, 8 (4): 122-126.

10. Yu Qian, Zhixiang Yao, Xiuxi Li.State Space 
Analysis of Chemical Process System [J]. Journal of South China University of Technology, 2003, 31 (11): 14-19.

11. Dengyou Xia, Qingchun Kang, Dingdou Jia , et al.Research on Determination and Application of Characteristics Importance of Petrochemical Storage Tank [J]. China Safety Science Journal, 2008, 18 (8): 80-84.

12. Bo Gong, Kaili Xu, Deshun Li.Study on iron ore hazard evaluation based on extension analytic hierarchy process $[\mathrm{J}]$. China Safety Science and Technology,2012, 8 (7): 83-88.

13. The 100 Largest Losses, 1972-2001:Large Property Damage Losses in the Hydrocarbon Chemical Industries [M]. London: Marsh Global Energy Risk Engineering, 2010.

14. D. Dibous and H. Prade. Fuzzy sets and systems: Theory and applications [M]. Academice Press, 1980. 